\title{
Entrevista com o Professor Stephen J. Ball
}

\author{
Prof. Dr. Jefferson Mainardes ${ }^{1}$ \\ Universidade Estadual de Ponta Grossa
}

(Tradução de Janete Bridon)

Stephen J. Ball é um dos mais renomados pesquisadores do campo da política educacional na atualidade. Até julho de 2015, ele ocupou a cátedra de Karl Mannheim Professor of Sociology of Education na UCL - Institute of Education (Londres). A partir de setembro de 2015, tornou-se Distinguished Service Professor of Sociology of Education. É membro da British Academy for the Humanities and Social Science (Academia Britânica de Humanidades e Ciências Sociais). Stephen J. Ball possui uma vasta lista de publicações $^{2}$. Esta entrevista foi realizada em Londres, no dia 21/09/2015. As questões foram divididas em três seções: questões epistemológicas de Política Educacional, preparação de futuros pesquisadores e elaboração de artigos de política educacional.

JM: Em 2010, foi criada a Red Latinoamericana de Estudios Epistemológicos en Política Educativa (ReLePe $)^{3}$. O principal objetivo dessa rede é promover estudos teóricos e epistemológicos de política educacional. Qual sua opinião sobre o desenvolvimento dos estudos teóricos de política educacional? Há ainda lacunas relevantes?

SJB: Penso que teoria é muito importante para o estudo de política. Precisamos de mais teoria, e de teoria de melhor qualidade. Penso que a maioria das análises de políticas, agora e historicamente, não tem sido muito sofisticada teoricamente ou, de fato, em muitos casos não é embasada por teoria alguma. Isso significa que muitas das análises de políticas importam para seu trabalho pressupostos implícitos sobre como o mundo funciona, sobre o que é a política, sobre o trabalho dos formuladores de políticas, sobre processos políticos - essas coisas são consideradas banais, elas não são discutidas - há um humanismo não reflexivo, um positivismo simples, uma ingenuidade sobre a linguagem - e isso significa que distorções são construídas na forma como as pessoas pensam e pesquisam..., pensam sobre a pesquisa em políticas. Por exemplo, eu penso que a maioria das análises de políticas é dominada por um pressuposto implícito, não discutido, de racionalidade, de que os processos de políticas são racionais, de que é um processo ordenado, coerente. E eu penso que isso traz distorções ao trabalho empírico

\footnotetext{
${ }^{1}$ Entrevista e notas explicativas: Prof. Dr. Jefferson Mainardes - Universidade Estadual de Ponta Grossa. E-mail: < iefferson.m@uol.com.br>.

${ }^{2}$ No site do Grupo de Pesquisa Políticas Educacionais e Práticas Educativas (www.uepg.br/gppepe), há uma lista dos textos e entrevistas de Stephen J. Ball publicados em Português e ainda uma lista de referências de pesquisas e publicações brasileiras que utilizam ideias de Ball. 
de muitos pesquisadores, eles presumem essa racionalidade quando se envolvem com a política. E muito do trabalho em política não é lá muito racional, ordenado nem muito bem organizado. Por isso, temos de pensar teoricamente sobre a possibilidade de irracionalidade, de confusão, de desordem, de caos. Isso também aponta para questões sobre o que conta como dado e as possibilidades do que podem ser dados. O que significa que precisamos pensar sobre a base ontológica da política, precisamos pensar sobre a relação da política com a maneira como pensamos sobre como o mundo social funciona, de forma mais geral. Assim, a teoria é muito importante. Por outro lado, há agora um conjunto muito interessante de trabalhos, particularmente na Austrália - que é re-trabalhar a base ontológica da pesquisa em política - feito por pessoas como Matthew Clarke, Taylor Webb, Kalervo Gulson e Greg Thompson ${ }^{4}$.

JM: No seu artigo Policy Sociology and Critical Social Research: a personal review of recent education policy and policy research (1997), você menciona dois tipos de epistemologia: epistemologia profunda e epistemologia de superfície. Você poderia explicar um pouco mais esses conceitos? Em sua opinião, é possível explorar a epistemologia profunda em um conjunto de publicações de Política Educacional ou mesmo focalizar na produção de um único pesquisador?

SJB: Então, o que eu quero dizer com epistemologia profunda está ligado ao que eu disse na última resposta, que política é um processo social, um processo relacional, um processo temporal, discursivo. É um processo revestido de relações de poder, é um processo político. Uma epistemologia profunda se envolveria com esses tipos de problemas e questões como base para o processo de política de interpretação. Então, com quais pressupostos de poder, de subjetividade, de verdade, o analista de política opera? Essas coisas entram em jogo em relação a todo e qualquer estudo, de uma forma ou de outra. Novamente, como eu disse antes, muitas vezes essas coisas são implicitamente construídas em estudos de política, e não abordadas diretamente. Afirmações não-identificadas do humanismo, do logocentrismo, do patriarcado e da representação são contrabandeadas. E assim nós acabamos com uma espécie de epistemologia de superfície, um conjunto de reflexões relativamente mundanas sobre o acesso a dados, o status de interpretação do ator, validação do entrevistado etc. Isso é bom, mas não vai longe o

\footnotetext{
${ }^{4}$ Uma das obras que poderia ser citada aqui é o livro Education Policy and Contemporary Theory: implications for research (GULSON; CLARKE; PETERSEN, 2015). É interessante destacar que na introdução os autores indicam que o livro foi escrito por pesquisadores e estudantes interessados no potencial crítico e criativo da teoria social na análise de políticas. Os objetivos do livro são: argumentar sobre a utilidade e a necessidade da teoria; celebrar o prazer e recompensas da teoria e oferecer modelos de uso da teoria na pesquisa sobre políticas educacionais. Indicam ainda que o livro complementa a literatura existente sobre o valor da teoria na pesquisa educacional (ANYON, 2009; BALL, 1995; DIMITRIADIS; KAMBERELIS, 2006; DRESSMAN, 2008; SIKES, 2006). Do mesmo modo, a preocupação central da ReLePe é o aprofundamento dos estudos teóricos e epistemológicos de política educacional.

Esse artigo foi publicado em Língua Portuguesa na Revista Currículo sem Fronteiras, em 2006 (v. 6, n. 2, p. 10-32) com o título Sociologia das políticas educacionais e pesquisa crítico-social: uma revisão pessoal das políticas educacionais e da pesquisa em política educacional. Foi também incluído no livro Políticas Educacionais: questões e debates (BALL; MAINARDES, 2011). Destaca-se a publicação do livro Educação Global S.A (BALL, 2014).
} 
suficiente. Você tem de pensar para além disso ou pensar mais profundamente do que isso. Com que tipos de sujeitos supomos que estamos lidando aqui? Qual é a base discursiva de sua interpretação? Temos uma visão de mundo que é uma visão construtivista? - a ideia de que o mundo emerge dos significados dos indivíduos - ou é estrutural - há algumas bases discursivas ou econômicas estruturais profundas para o mundo que estamos estudando? Mais uma vez, isso levanta questões sobre o que conta como dado, e como vamos "registrar" os dados, como representamos o significado? É para mim nesse nível que um indivíduo está envolvido com uma epistemologia profunda. Então, você pode olhar para quase qualquer trabalho e pensar nisso nesses termos, olhar para qualquer pressuposto implícito ou explícito sobre como as pessoas são, como o mundo funciona, o que políticas significam.

JM: A questão é que, quando tentamos analisar artigos e publicações de Política Educacional em termos epistemológicos, algumas vezes enfrentamos dificuldades e desafios porque, de modo geral, os autores não explicitam os aspectos epistemológicos da sua pesquisa. Temos tentado desenvolver metapesquisa, mas tem sido uma tarefa complexa e difícil ${ }^{6}$. Em seu artigo What is policy? 21 years later: reflections on the possibilities of policy research $(2015)^{7}$ você escreve: "Tendemos a limitar nossa ambição e ficar na superfície das coisas, tomando política pelo valor nominal e reinscrevendo suas afirmações para dar coerência às nossas análises, em vez de procurar abordar $A$ Ordem das Coisas (Foucault, 1970)". Essa reflexão pode ser generalizada para o campo da Política educacional em geral?

SJIB: Sim, eu penso que sim. A frase "a ordem das coisas" é uma alusão ao livro de Foucault, As Palavras e as Coisas ${ }^{8}$. E portanto o que eu estou sugerindo, aludindo, é que talvez nós precisemos pensar epistemicamente no sentido de Foucault. Nós temos de pensar sobre as epistemes que sustentam e tornam possíveis certas afirmações sobre a verdade da política. Os fundamentos para que declarações sejam consideradas verdadeiras ou falsas. E, no momento, pode-se argumentar - eu tenho pensado um pouco sobre isso..., com base no trabalho de Foucault ...- que entramos agora em uma espécie de quarta episteme. Ele falou sobre três períodos epistêmicos em As Palavras e as Coisas, culminando no período moderno. No entanto, talvez, pensando em alguns de seus trabalhos posteriores, estejamos agora dentro de uma episteme neoliberal. E, dentro disso, há certas premissas sobre a verdade; as declarações que contam como verdades são, no fundo e apenas, aquelas que se referem ao funcionamento do mercado - que têm a ver com concorrência, escolha, investimento e responsabilidade, produtividade e eficiência.

\footnotetext{
${ }^{6}$ Mais informações sobre o enfoque das epistemologias da política educacional e metapesquisa podem ser encontrados em Tello (2012) e Tello e Mainardes (2012, 2015).

O título do artigo é $O$ que é política? 21 anos depois: reflexões sobre as possibilidades da pesquisa sobre politicas. Em inglês, foi publicado em Discourse: studies in the cultural politics of educations, v. 36, n. 3, p. 306-313, 2015.

${ }^{8}$ No original em francês, Les mots et les choses; o título da publicação em inglês é, em tradução literal, "A ordem das coisas" (The Order of Things).
} 
Isso envolve olhar novamente para além das características de superfície da política, para começar a entender essas características epistêmicas neoliberais da política. Então, é isso que eu estou sugerindo.

JM: Na ReLePe, estamos também interessados em analisar a constituição do campo da política educacional em nossos países (Brasil, Argentina, Colômbia, Chile, México etc.). Na sua percepção, a Política Educacional pode ser considerada um campo de conhecimento específico? Alguns pesquisadores consideram como sendo uma disciplina ou mesmo como parte da Sociologia da Educação (como parece ser o caso no Reino Unido).

SJIB: Essa é uma questão muito difícil, porque a Sociologia da Educação é agora um campo tão díspar de conhecimento, não há muita coerência, é uma combinação muito frouxa de toda uma gama de diferentes tipos de trabalho, diferentes pontos de foco, níveis de análise, perspectivas teóricas, ontologias. Eu não acho que haja qualquer coisa que você possa rotular ou descrever de uma forma muito simples sobre a Sociologia da Educação. E, se você olhar na outra direção, sim, você pode falar sobre estudos de política educacional como um campo de pesquisa, mas imediatamente se levanta a questão sobre a relação da política educacional com outros tipos de política - e para outras possibilidades analíticas - como, por exemplo, analistas de políticas educacionais não são bons em lidar com dinheiro - e nós poderíamos querer buscar em Harvey, Larner, Peck e Brenner e Jessop insights sobre a economização e a geografia da política. Particularmente, se você leva o neoliberalismo muito a sério, então, como Tony Blair colocava, quando ele era primeiro-ministro no Reino Unido, "a Educação é a nossa melhor política econômica"; nesse sentido, você pode argumentar que a análise de políticas educacionais é, na verdade, uma espécie de subconjunto de análise da política econômica. Então, você poderia fazer uma proposta mais coerente em torno da relação da política educacional com outros tipos de análise política, em vez de com a Sociologia da Educação. Contudo, isso também depende de tradições nacionais e da organização do conhecimento, e de como suas relações verticais e horizontais ...-como Basil Bernstein colocaria...- são organizados em determinados locais. Então, é difícil responder a isso. Igualmente, você tem de pensar se é uma questão importante. É importante que existam distinções claras e demarcações entre áreas de investigação? Ou, talvez, poderia ser mais produtivo minimizá-las e pensar de uma forma pós-disciplinar, pós-filosófica sobre teoria e análise, baseando-se em discernimentos e possibilidades de diferentes teorias e disciplinas, unindo-as - uma teorização mais plural e diversificada.

\footnotetext{
Até o presente (2015), não houve no Brasil e na América Latina um debate em torno da questão se a Política Educacional é ou não um campo específico de conhecimento ou campo acadêmico. Na literatura internacional, autores como Cibulka (1994), Ladwig (1994), Lingard, Rawolle e Taylor (2005) têm considerado a Política Educacional como um campo. Mais recentemente, Lingard e colaboradores, com base na teoria dos campos sociais de Bourdieu, consideram que há um campo global das políticas educacionais (ex.: RAWOLLE; LINGARD, 2015; SELLAR; LINGARD, 2014), bem como políticas educacionais globais. Azevedo e Aguiar (2001), Mainardes (2009); Santos e Azevedo (2009, 2012), Krawczyk (2012), Tello $(2012,2013,2014)$, Schneider (2014) e Souza (2014) também se referem à política educacional como campo. Tello (2013) refere-se à política educacional como campo teórico. Oliveira (2011) refere-se a políticas públicas em educação.
} 
JM: Uma das questões que emergiu a partir das discussões e pesquisas da ReLePe está relacionada ao objeto(s) de estudo da Política Educacional. Em sua opinião, qual é o objeto(s) de estudo da Política Educacional?

SJB: O objeto de estudo é construído pela epistemologia com a qual você opera. Por um lado, pode ser que você esteja interessado nos significados e nas interpretações de atores de política. Ou você poderia estar interessado nos princípios epistemológicos que dão origem à verdade e à falsidade na política e a várias outras coisas entre elas. É uma questão sobre o tipo de decisões que você toma sobre a sua posição epistemológica, que, então, constrói o objeto de estudo; da forma que Foucault sugere que os corpos de conhecimento constroem os objetos sobre os quais eles falam. Um bom exemplo na pesquisa de política é a "implementação" - há uma tradição firmemente arraigada de pesquisa de implementação, que interpreta a política como um processo hiperracional e linear, em cujo "final" encontramos "falhas" de implementação. Essa é uma concepção da política que eu tento contrariar e ridicularizar em How Schools do Policy ${ }^{10}$, e construir o objeto de estudo de uma forma totalmente diferente - como enactment ${ }^{11}$.

JM: Talvez seja difícil definir um objeto específico, fixo...

SJB: Diferentes versões de estudos de políticas constroem o objeto de conhecimento de forma diferente e de maneiras as mais diversas. No Reino Unido, por muitos anos a análise de políticas centrou-se no trabalho de governo, e a política foi quase vista como sinônimo de governo - no sentido tradicional da palavra. Entretanto, agora nós compreendemos o que conta como política de maneiras diferentes, e eu tenho tentado argumentar que a política é construída e feita em todos os tipos de arenas, em todos os tipos de níveis, por todos os tipos de pessoas; de forma que o objeto de estudo torna-se dissipado ou tem de ser entendido em termos de uma análise de trajetória; como estando em movimento pelo tempo e pelo espaço. A maneira como construímos nosso objeto de estudo também antecipa os projetos e os métodos de pesquisa que usamos para nos envolver com ele.

\footnotetext{
${ }^{10}$ How do schools do policy: policy enactments in Secondary Schools, de Stephen J. Ball, Meg Maguire, Annette Braun, publicado em 2012 pela Editora Routledge.

${ }^{11} \mathrm{O}$ termo 'policy enactment' é de difícil tradução. Em uma entrevista com o Prof. Stephen J. Ball, publicada em 2009, explicamos que "esta palavra tem sido usada no contexto legal para descrever o processo de aprovação de leis e de decretos. $\mathrm{Na}$ entrevista, Ball usou a palavra no sentido teatral, referindo-se à noção de que o ator possui um texto que pode ser apresentado/representado de diferentes formas. O texto, no entanto, é apenas uma pequena parte (porém, uma parte importante) da produção. Ball usou esse termo para indicar que as políticas são interpretadas e materializadas de diferentes e variadas formas. Os atores envolvidos (no caso, os professores) têm o controle do processo e não são 'meros implementadores' das políticas" (MAINARDES; MARCONDES, 2009). Rosa (2012) considera que a melhor tradução para policy enactment seja "encenação das políticas". Temos também utilizado o conceito de "política em ação" para nos referirmos à política que está sendo efetivamente desenvolvida na escola.
} 
JM: Agora, temos uma questão sobre "big and small theories" (grandes e pequenas teorias), uma ideia que considero importante. Você poderia explorar um pouco mais essa ideia e como você a tem aplicado em suas pesquisas?

SJIB: Bem, isso traz de volta o que eu quero dizer com epistemologia profunda. Classicamente, "small theory" (teoria pequena) é uma teoria interpretativa. É sobre atores e seus relacionamentos. Eu não estou dizendo que não é importante; eu penso que é importante entender como os atores constroem sentido na política e, então, como agem em relação a essa tomada de sentido. Certamente, isso está se tornando uma abordagem muito comum, até mesmo muito dominante na análise de políticas, e também tem uma longa história com base na realização de entrevistas com os formuladores de políticas etc. No entanto, por outro lado, "big theory" (teoria grande") leva em direções ligeiramente diferentes, geralmente a algum tipo de direção estruturalista. E, obviamente, o marxismo é uma grande teoria, nesse sentido, que vê a elaboração de políticas como fundamentalmente dependente tanto do equilíbrio de forças dentro de lutas de classes, ou relacionada a determinada constituição dos meios de produção em qualquer período de tempo. Igualmente, a Teoria do Discurso leva em direção ao tipo de questões epistêmicas às quais eu me referi anteriormente, o que envolve olhar para os fundamentos cujas alegações sobre a verdade são justificadas e para como sujeitos de políticas são produzidos, como são falados pelo discurso, como eles são formados e re-formados pela política e convidados ou convocados para falar, agir, ler, trabalhar, pensar, sentir, comportar-se, valorizar, desejar. Isto é, as formas pelas quais a política é construída na linguagem, por meio de práticas e relações sociais específicas - relações de poder - e formas e estruturas de organização específicas. Então, é isso que eu quero dizer com teorias maiores - é muito mais ambicioso, tanto em sua profundidade como em sua amplitude, pois envolve ir em direção ao que Foucault chamaria de um "dispositif" ou um "apparatus", ou o que Deleuze diz sobre assemblage (agenciamento) $)^{12}$. Políticas são agenciamentos de valores instáveis, autoridade, significados e práticas, os quais reúnem vários estados de coisas e organismos, bem como declarações, modos de expressão, e regimes inteiros de sinais - tanto objetos materiais quanto imateriais. Então, você não pode mais simplesmente se preocupar com uma tecnologia ou uma política, você tem de ver essas coisas em uma relação complexa de objetos, de pessoas, de práticas de

\footnotetext{
12 De acordo com Wise (2005, p. 77), “assemblage (agenciamento), como é utilizado na obra de Deleuze e Guattari, é um conceito que lida com o jogo de contingência e estrutura, organização e mudança" (p. 77). O termo em francês é agencement, normalmente traduzido como "juntar", "arranjo", "dispor", "disposição" ou "encaixar". É importante destacar que agencement "não é um termo estático; não é o arranjo ou a organização, mas o processo de arranjar, organizar, juntar. (...) Assemblage não é um conjunto de partes pré-determinadas (tais como as peças de um avião de plástico) que são, então, colocadas juntas em ordem ou em uma estrutura já concebida (o modelo de avião). Também assemblage não é uma coleção aleatória de coisas, já que há um sentido de que assemblage é um todo de algum tipo que expressa alguma identidade e reivindica um território. Assemblage é um devir que reúne elementos" (WISE, 2005, p. 77). Youdell (2015) explica que Deleuze e Guattari utilizam noções de "agrupamentos", "arranjos" e "assemblages" "para pensar sobre a multiplicidade de elementos diversificados e móveis que se combinam para constituir formações sociais complexas. Eles sugerem que aparentemente entidades inteiras, e a 'educação' pode ser tal entidade, podem ser entendidas como assemblages de componentes heterogêneos que atravessam a ordem econômica, política, estado, social, institucional, linguística, semiótica, representacional, discursiva, subjetiva e afetiva. Tais componentes têm sido, muitas vezes, tratados como separados ou de importância diferencial em ciências sociais, mas, para Deleuze e Guattari (1983: 52), eles são inseparáveis” (YOUDELL, 2015, p 111).
} 
linguagem, relacionando-os como uma espécie de todo mais ou menos coerente. Essa não é uma rearticulação do macro e do micro, mas um apagamento desse binário para ver a política como um conjunto de técnicas, categorias, objetos e subjetividades. Essa é uma concepção muito material do discurso que não prioriza a "leitura" dos textos, mas sim lida tanto com as condições de possibilidade e contingência histórica quanto com a maneira como o discurso é escrito em corpos.

JM: Até agora, a ReLePe já realizou três eventos. O último foi o I Encuentro Latinoamericano de Profesores de Política Educativa ${ }^{13}$, realizado na Unifesp, em Guarulhos, nos dias 6 e 7 de julho de 2015. Uma das questões discutidas no evento foi a formação de pesquisadores para o campo da Política Educacional (Mestrado, Doutorado, etc.). Em sua opinião, quais aspectos são relevantes para serem considerados na formação de futuros pesquisadores de Política Educacional?

SJIB: Penso que a resposta simples para isso é fazê-los ler a teoria. O que eu observo muito frequentemente com os meus alunos pesquisadores quando eles chegam, é que eles estão interessados em um objeto de estudo, eles estão interessados em privatização ou em escolha dos pais ou na introdução de relações de gerenciamento para a governança do Ensino Superior, ou em estudantes da classe trabalhadora em universidades de elite, o que quer que seja - eles têm um tema de estudo e eles o concebem de uma forma bastante direta, empírica. Eles pensam: "Vou perguntar a algumas pessoas sobre isso e elas irão me dizer como é". Contudo, muitas vezes, quando eu os faço ler teoria, eles na verdade acabam repensando, de certa forma, todo o seu projeto e, às vezes, "reconceitualizam" seus objetos de estudo. Então, eu penso que ser teoricamente alfabetizado e ser capaz de pensar além do objeto de estudo, como é conceitualizado, é realmente o mais importante. E isso é transponível, porque você pode então usar seus recursos teóricos para outros estudos que abordam diferentes temas e problemas. Isso não significa que você tem de se comprometer com uma posição teórica. Você pode desenvolver um arsenal de conceitos, técnicas e métodos de teorias diferentes, desde que tenha algum grau de coerência em seu trabalho. Você pode usá-lo em relação a quaisquer objetos de estudo. Então, eu penso que é a preparação mais importante para a análise de políticas, para estudantes de pesquisa de políticas..., é que eles leiam muita teoria. A minha experiência também é que, se os alunos leem muita teoria, eles normalmente acabam encontrando algo que funciona para eles, e isso é que é importante. Eu não vejo isso como uma espécie de compromisso, como uma identidade. Quando eu era um pesquisador jovem, esperava-se que você assumisse uma identidade acadêmica - que era mostrada em sua escrita - com base em algum tipo de compromisso teórico. Então, você podia ser um neomarxista, ou simbólico interacionista ou feminista. Eu não acho que isso seja mais um

\footnotetext{
Os anais do I Encuentro Latinoamericano de Profesores de Política Educativa estão disponíveis em www.encuentrorelepe. com.br. Informações sobre as Jornadas Latinoamericanas de Estudios Epistemológicos en Política Educativa, realizadas em 2012 (Buenos Aires) e 2014 (Curitiba) podem ser encontradas em: www.relepe.org.
} 
corte tão claro. Essas expectativas não são tão fortes, e muitos pesquisadores sentem-se desconfortáveis em identificar-se com uma única posição teórica. Contudo, isso significa que é importante ter algum grau de reflexividade sobre as decisões que você faz em relação à pesquisa, aos dados, à escrita. O que é importante é adquirir e desenvolver um conjunto de ferramentas teóricas que funcionem, que sejam úteis, que tenham poder em relação àquilo que você está tentando entender.

JM: Tive a oportunidade de ouvir as suas respostas a perguntas no site do Journal of Education Policy ${ }^{14}$ que servem para apresentar o Journal e para orientar colaboradores. Temos uma questão mais ou menos similar, já respondida no site. Em sua opinião, quais são as principais caraterísticas de um bom artigo sobre Política Educacional?

SJB: Essa é uma pergunta difícil, porque um artigo pode ser formulado com objetivos diferentes. Poderia ser uma tentativa de desenvolver uma perspectiva teórica em relação à análise de políticas. Ou poderia ser parte de um trabalho empírico. No entanto, se é empírico, então, com base no que eu venho dizendo, deveria ser algo que permita ao o leitor compreender a base em que o autor constrói seu objeto de estudo e ver as formas pelas quais esses pressupostos, essas premissas habilitam e constrangem o pesquisador em termos do que ele é capaz de dizer sobre seus objetos de estudo. Então, para mim, no outro extremo, uma das coisas importantes é ter algum grau de modéstia sobre o que você é capaz de atingir e o que você afirma ser capaz de fazer. Eu penso que muitos pesquisadores de políticas dão crédito demais à sua investigação - eles fazem afirmações que não são muito bem fundamentadas empiricamente e nem, por certo, epistemológica ou teoricamente. Então eu acho que é preciso haver mais reflexividade em relação a tais artigos - é o tipo de coisa que Bourdieu, por exemplo, sempre defendeu, que é preciso haver uma compreensão de base sociopolítica da produção do trabalho intelectual. E ele também foi muito claro sobre o que ele estava fazendo ser um empreendimento muito modesto - ele não falou de desenvolver teorias, mas de fazer conjuntos de experiências. E ele nunca alegou ter produzido qualquer teoria social grandiosa, do mesmo modo que Foucault nunca reivindicou ter escrito uma teoria social. Foucault falou sobre a construção de conhecimento estratégico com um tijolo de cada vez. É isso que penso que precisamos - precisamos de mais construção de paredes e menos afirmações sobre a construção de casas de má qualidade e palácios sem alicerces... nós precisamos ser mais modestos... e, então, poderemos chegar a algum lugar.

JM: Muito obrigado, Professor Ball, pela entrevista. Com certeza, ela será muito útil para os pesquisadores de política educacional.

O Journal of Education Policy foi criado em 1986. É um dos mais importantes periódicos de Política Educacional. No site http://www.tandfonline.com/loi/tedp20, o Professor Stephen J. Ball, na qualidade de editor, responde a uma série de perguntas sobre o periódico. 


\section{Referências}

ANYON, J. Theory and educational research: Toward critical social explanation. London: Routledge, 2009.

AZEVEDO, J. M. L. de; AGUIAR, M. A. A produção do conhecimento sobre a política educacional no Brasil: um olhar a partir da ANPED. Educação \& Sociedade, Campinas, v. 22, n. 77, p. 49-70, set./dez. 2001.

BALL, S. J. Educação global S.A.: novas redes políticas e o imaginário neoliberal. Ponta Grossa: Editora UEPG, 2014.

BALL, S. J. Intellectuals or technicians? The urgent role of theory in Educational Studies. British Journal of Educational Studies, v. 43, n. 3, p. 255-271, 1995.

BALL, S. J.; MAINARDES, J. Políticas Educacionais: questões e dilemas. São Paulo: Cortez, 2011.

CIBULKA, J. G. Policy analysis and the study of the politics of education. Journal of Education Policy, v. 9, n. 5, p. 105-125, 1994.

DIMITRIADIS, G.; KAMBERELIS, G. Theory for education. New York: Routledge, 2006.

DRESSMAN, M. Using social theory in educational research: A practical guide. New York and London: Routledge, 2008.

GULSON, K. N.; CLARKE, M.; PETERSEN, E. B. (Eds.). Education policy and contemporary theory: implications for research. Abingdon: Routledge, 2015.

KRAWCZYK, N. A historicidade da pesquisa em política educacional: o caso do Brasil. Jornal de Políticas Educacionais, Curitiba, v. 6, n. 12, p. 3-11, jul./dez. 2012.

LADWIG, J. G. For whom this reform?: outlining educational policy as a social field. British Journal of Sociology of Education, v. 15, n. 3, p. 341-363, 1994.

LINGARD, B.; RAWOLLE, S.; TAYLOR, S. Globalizing policy sociology in education: working with Bourdieu. Journal of Education Policy, v. 20, n. 6, p. 759-777, 2005.

MAINARDES, J. Análise de políticas educacionais: breves considerações teórico-metodológicas. Contrapontos, Itajaí, v. 9, n. 1, p. 4-16, jan./abr. 2009.

MAINARDES, J; MARCONDES, M. I. Entrevista com Stephen J. Ball: um diálogo sobre justiça social, pesquisa e política educacional. Educação \& Sociedade, Campinas, v. 30, n. 106, p. 303-318, jan./abr. 2009. 
OLIVEIRA, D. A. As políticas públicas em educação e a pesquisa acadêmica. In: DUARTE, A.; OLIVEIRA, D. A. (Orgs.). Políticas públicas e educação: regulação e conhecimento. Belo Horizonte: Fino Traço, 2011, p. 71-89 (Educere, 9).

RAWOLLE, S.; LINGARD, B. Bourdieu and doing policy sociology in education. In: GULSON, K. N.; CLARKE, M.; PETERSEN, E. B. (Eds.). Education policy and contemporary theory: implications for research. Abingdon: Routledge, 2015. p. 15-26.

ROSA, S. S. Reformas educacionais e pesquisa: as políticas "em cena" no Brasil e na Inglaterra. E-curriculum, São Paulo, v. 8, n. 2, p. 1-28, 2012.

SANTOS, A. L. F.; AZEVEDO, J. M. L. A Pós-Graduação no Brasil, a pesquisa em educação e os estudos sobre a política educacional: os contornos da constituição de um campo acadêmico. Revista Brasileira de Educação, Rio de Janeiro, v. 14, n. 42, p. 534-550, set./dez. 2009.

SANTOS, A. L. F.; AZEVEDO, J. M. L. de. Regulação e legitimação da pesquisa sobre a política educacional como campo acadêmico: um estudo a partir dos programas de Pós-Graduação do nordeste brasileiro. In: GOMES, A. M.; OLIVEIRA, J. F. de (Orgs.). Reconfiguração do campo da educação superior. Campinas: Mercado de Letras, 2012. p. 71-93. (Série Estudos em Políticas Públicas e Educação).

SCHNEIDER, M. P. Pesquisa em política educacional: desafios na consolidação de um campo. Revista Educação (PUC-Campinas), Campinas, v. 19, n. 1, p. 5-13, jan./ abr. 2014.

SELLAR, S.; LINGARD, B. The OECD and the expansion of PISA: new global modes of governance in education. British Educational Research Journal, v. 40, n. 6, p. 917-936, 2014.

SIKES, P. Towards useful and dangerous theories. Discourse: Studies in the Cultural Politics of Education, v. 27, n. 1, p. 43-51, 2006.

SOUZA, A. R. A pesquisa em políticas educacionais no Brasil: de que estamos tratando? Práxis Educativa, v. 9, n. 2, p. 355-367, jul./dez. 2014.

TELLO, C. Las epistemologías de la política educativa: vigilancia y posicionamiento epistemológico del investigador en política educativa. Práxis Educativa, Ponta Grossa, v. 7, n. 1, p. 53-68, jan./jun. 2012.

TELLO, C. El campo teórico de la política educacional: modelos, abordajes y objetos de estudio. Jornal de Políticas Educacionais, Curitiba, n. 14, p. 62-75, jul./dez. 2013.

TELLO, C. The theoretical field of education policy: characteristics, objects of study, and mediations. A Latin American perspective. American Journal of Educational Research, v. 2, n. 4, p. 197-203, 2014. 
TELLO, C. ; MAINARDES, J. La posición epistemológica de los investigadores en Política Educativa: debates teóricos en torno a las perspectivas neo-marxista, pluralista y pos-estructuralista. Archivos Analíticos de Políticas Educativas, v. 20, n. 9, p. 1-31, 2012.

TELLO, C.; MAINARDES, J. Revisitando o enfoque das epistemologias da política educacional. Práxis Educativa, Ponta Grossa, v. 10, n. 1, p. 153-178, jan./jun. 2015.

WISE, J. M. Assemblage. In: STIVALE, C. J. Gilles Deleuze: key concepts. Montreal: McGuill-Queens University Press, 2005. p. 77-87.

YOUDELL, D. Assemblage theory and education policy sociology. In: GULSON, K. N.; CLARKE, M.; PETERSEN, E. B. (Eds.). Education policy and contemporary theory: implications for research. Abingdon: Routledge, 2015. p. $110-212$.

Recebido em: 20/10/2015

Aprovado em: 23/11/2015 